\title{
Modeling of Pt-catalyst surface influence on characteristics of oxygen and carbon monoxide molecules
}

\author{
Kostrobij P. ${ }^{1}$, Beznosiuk A. ${ }^{1}$, Dmytruk V. ${ }^{1,2}$, Polovyi V. ${ }^{1}$ \\ ${ }^{1}$ Lviv Polytechnic National University \\ 12 S. Bandera str., 79013, Lviv, Ukraine \\ ${ }^{2}$ Centre of Mathematical Modelling of Pidstryhach IAPMM \\ of National Academy of Sciences of Ukraine \\ 15 Dudayev str., 79005, Lviv, Ukraine
}

(Received 30 June 2016)

\begin{abstract}
A simple mathematical model of Pt-catalyst surface influence on both carbon monoxide and oxygen molecules behavior is considered. It is shown that an electric field, which is located in a near-surface layer of the Pt-catalyst, leads to a significant change of both the dipole moment and the equilibrium interatomic distance.
\end{abstract}

Keywords: diatomic molecule in electric field, catalyst phenomenon, semi-bounded metal.

2000 MSC: $00 \mathrm{~A} 71$

UDC: $533.9,536.7$

\section{Introduction}

A significant number of theoretical and experimental researches are devoted to investigation of carbon monoxide $(\mathrm{CO})$ oxidation processes kinetics on a metal catalysts surface (based on platinum, palladium, ruthenium) [1]. Nevertheless, the research of these processes remains urgent both from the viewpoint of experimental investigations at nanocatalytic level and theoretical viewpoint because a consequent microscopic theory of reactive diffusion processes has not been investigated enough yet. Without understanding catalytic $C O$ oxidation mechanisms on a microscopic scale, the development of a mathematical model of a quantitative description of catalytic $C O$ oxidation process is impossible.

The catalytic $C O$ oxidation mechanisms (Langmuir-Hinshelwood (LH) [2], Eley-Rideal (ER) [3]) were investigated in [4]. According to the LH mechanism both reactants $\left(\mathrm{CO}\right.$ and $\left.\mathrm{O}_{2}\right)$ are adsorbed on a metal catalyst surface in the beginning and then between adsorbed $C O_{a d}$ and $O_{a d}$ under thermodynamically advantageous conditions a fusion reaction with a quick desorption process of the resultant product $\left(\mathrm{CO}_{2}\right)$ from the catalyst surface occur. The $\mathrm{CO}$ oxidation process through the ER mechanism occurs when oxygen atoms are adsorbed on the catalyst surface and a $C O$ molecule is located in a subsurface gas zone. The energy barrier of the reaction according to such a mechanism is $0.72 \mathrm{eV}$ and according to $\mathrm{LH}$ mechanism it is larger $(0.8-1.05 \mathrm{eV})$. However, experimental investigations show that for $C O$ oxidation processes on a platinum catalyst, $\mathrm{LH}$ mechanism is more acceptable. Although, the minimum barrier energy of a reaction for ER mechanism is less than for LH mechanism, such factors as the $C O$ molecule structure, its orientation near a catalyst surface begin to play a determinant role. Detailed microscopic analysis of $C O$ oxidation mechanisms on a platinum catalyst surface was conducted in [5-7] and an impurity effect on a catalytic $C O$ oxidation was considered in [8].

ZGB model [9] and its generalization [10] a basis for theoretical investigation of catalytic $C O$ oxidation kinetics being considered. This model assumes that a $C O$ oxidation reaction occurs only on a catalyst surface, moreover, an adsorption of oxygen atoms occurs in consequence of a $\mathrm{O}_{2}$ molecule decomposition near the catalyst surface. The $C O$ molecule is adsorbed by the surface and lies on it without decomposing into atoms. However, as shown in [11], near a metal catalysts surface there exists 
a strong electrostatic field (with the intensity $40 \mathrm{~V} / \mathrm{nm}$ ), which localization is the same as the atomic number of the metal catalyst. The influence of this field on a diatomic molecule $\left(\mathrm{CO}\right.$ or $\left.\mathrm{O}_{2}\right)$ can lead to its decomposition into atoms that henceforth can be adsorbed by the surface of metal catalysts.

In this work, a simple mathematical model of a diatomic molecule near a metal catalyst surface is developed and investigated. It is shown that existing near-surface electric field affects an equilibrium distance $R$ between molecule atoms (leads to its increase), that implies a possibility of molecule decomposition into atoms with a consequent adsorption of $\mathrm{O}_{2}$ molecule by the surface.

\section{Problem formulation}

Let us consider a motion of a diatomic molecule $\left(\mathrm{CO}\right.$ or $\left.\mathrm{O}_{2}\right)$ near a metal catalyst surface. The diatomic molecule contains atoms with atomic numbers $Q_{1}$ and $Q_{2}$ respectively, and set of electrons which general number is $Q_{1}+Q_{2}$.

Whereas the metal catalyst is macroscopically large comparing to a size of the molecule, further let us assume that it is located in the lower half-space $Z<0(O X Y Z$ is the Cartesian coordinate system connected to the catalyst) with a flat surface $Z=0$ (Fig. 1).

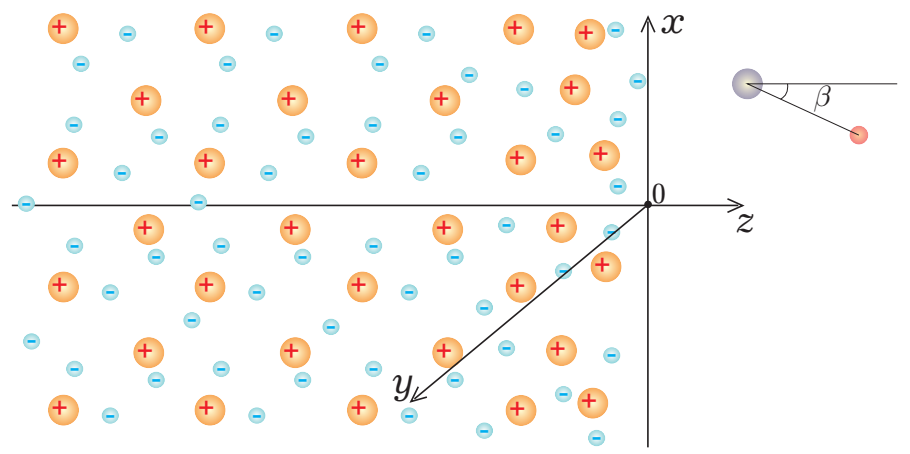

Fig. 1. Diatomic molecule near metal catalyst surface.

As shown in [13], near the surface of metal there exists a non-uniform electric field with the intensity $E(\boldsymbol{r})$.

In dipole approximation [14], the energy $W$ of diatomic molecule in an internal electric field of the intensity $E(\boldsymbol{r})$ can be expressed as follows:

$$
W=W_{0}+\frac{1}{2} \int_{V} \varphi(\boldsymbol{r}) \rho(\boldsymbol{r}) d \boldsymbol{r}-\int_{V}(\boldsymbol{d}(\boldsymbol{r}), \boldsymbol{E}(\boldsymbol{r})) d \boldsymbol{r} .
$$

Here $W_{0}$ is a molecule energy at the moment when electric field is absent, $\rho(\boldsymbol{r})$ is the electric charge density, $\varphi(\boldsymbol{r})$ and $\boldsymbol{E}(\boldsymbol{r})$ are the potential and the intensity of the electric field respectively, $\boldsymbol{d}(\boldsymbol{r})$ is the dipole moment of the molecule, $($,$) is a scalar product.$

The diatomic molecule density of the electric field is

$$
\rho(\boldsymbol{r})=\rho^{e}(\boldsymbol{r})+Q_{1} e \delta\left(\boldsymbol{r}-\boldsymbol{R}_{1}\right)+Q_{2} e \delta\left(\boldsymbol{r}-\boldsymbol{R}_{2}\right) .
$$

Here $\boldsymbol{R}_{1}$ and $\boldsymbol{R}_{2}$ are coordinates of the nucleus atoms of the molecule in Cartesian coordinate system tied to the catalyst, $e$ is electron charge, $\delta()$ is Dirac delta function [14].

Let us assume that the dipole moment of the molecule is a constant vector. It allows us to write the expression for the dipole moment in the presence of the electric field in the following form

$$
\boldsymbol{d}(\boldsymbol{r})=\left(d_{0}+\varepsilon_{0} \alpha \boldsymbol{E}\right) \delta\left(\boldsymbol{r}-\boldsymbol{R}^{d}\right) \boldsymbol{n},
$$


where $d_{0}$ is an absolute value of the dipole moment, $\varepsilon_{0}$ is the vacuum permittivity, $\alpha$ is the molecule polarization, $\boldsymbol{n}$ is a unit direction vector (in our case under influence of a field, created by the surface, the direction is perpendicular to the surface). Let us consider that dipole moment is concentrated in the molecule center of the charge $\boldsymbol{R}^{d}$, which we denote by

$$
\boldsymbol{R}^{d}=\frac{Q_{1} \boldsymbol{R}_{1}+Q_{1} \boldsymbol{R}_{2}}{Q_{1}+Q_{2}}
$$

For the chosen model of catalyst in case of a plane surface, the electrostatic potential is $\varphi(\boldsymbol{r}) \equiv \varphi(z)$, and $E(\boldsymbol{r}) \equiv E(z)$ [15], where $z$ is a coordinate of the $O z$ axis that is perpendicular to the surface of catalyst.

Considering this, let us rewrite the expression (3) as follows:

$$
W-W_{0}=\frac{1}{2} \int_{V} \varphi(z) \rho^{e}(\boldsymbol{r}) d \boldsymbol{r}-\frac{1}{2} e\left(Q_{1} \varphi\left(z_{1}\right)+Q_{2} \varphi\left(z_{2}\right)\right)-d_{0 z} E\left(z_{d}\right)-\varepsilon_{0} \alpha E^{2}\left(z_{d}\right),
$$

where $d_{0}$ is a dipole moment projection of the molecule onto $O z$ axis.

\section{Calculation of the electronic density, the electrostatic potential and intensity}

The electronic density of molecules has been calculated using a software package Firefly (old name is PC GAMESS) [18]. In Fig. 2, it is shown scalar surfaces of the electronic density of $C O$ molecule and in Fig. 3 of $\mathrm{O}_{2}$. Note that the scalar surfaces of the electronic density for $\mathrm{CO}$ coincide with results of analogical calculations given in [16].

The electrostatic potential $\varphi(z)$ in our model (Fig. 1) is a solution of Poisson's equation [15]:

$$
\frac{d^{2} \varphi(z)}{d z^{2}}=-4 \pi e n\left(F_{1}(z)-F_{\text {ion }}(z)\right)
$$

or

$$
\varphi(z)=\varphi(-\infty)+4 \pi e n \int_{-\infty}^{z} d z^{\prime}\left(z^{\prime}-z\right)\left(F_{1}\left(z^{\prime}\right)-F_{\text {ion }}\left(z^{\prime}\right)\right) .
$$

Here $F_{1}(z)$ is a unary distribution function of electrons, $n F_{i o n}(z) \equiv \frac{2 N}{S L} e \theta\left(-z-m_{d}\right)$ is a unary distribution function of positive compensated charge, $m_{d}>0$ is a parameter that is determined by the electroneutrality condition:

$$
\int_{-\infty}^{\infty} d z\left(F_{1}(z)-F_{\text {ion }}(z)\right)=0
$$

The unary distribution function $F_{1}(z)$ was calculated in the research [17]. Knowing $F_{1}(z)$ it is possible to write the intensity of induced electrostatic field as follows

$$
E(z)=-\frac{d \varphi(z)}{d z}=-4 \pi e n \int_{-\infty}^{z} d z^{\prime}\left(n\left(z^{\prime}\right)-n(z)\right)
$$

Here $n(z)$ is defined according to the condition $F_{1}(z)=e n(z)$.

$\varphi(\boldsymbol{r})$ and $E(\boldsymbol{r})$ were calculated using the results obtained in [17] for the unary function $F_{1}(z)$. Results of these calculations in accordance with Gell-Mann-Brueckner parameter $r_{s}$ [14] are presented in Figs. 4 and 5. 


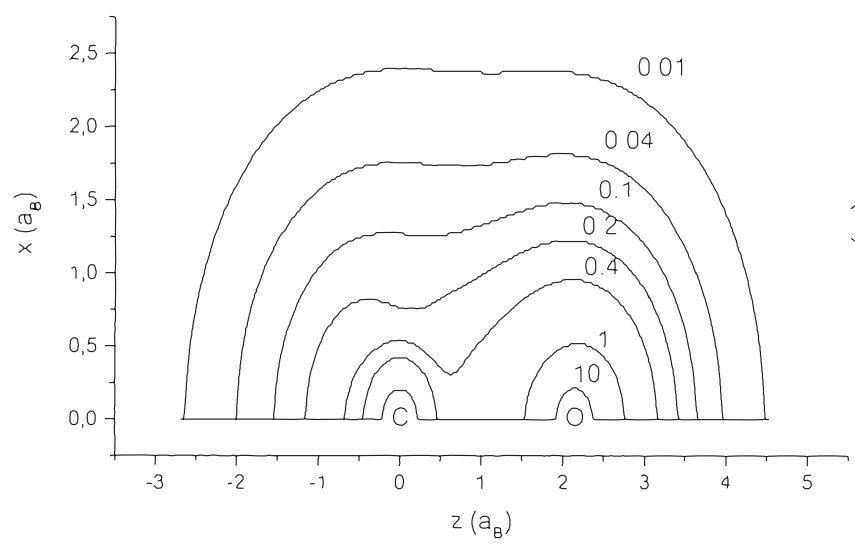

Fig. 2. Electronic density of $C O$ molecule obtained by using Firefly.

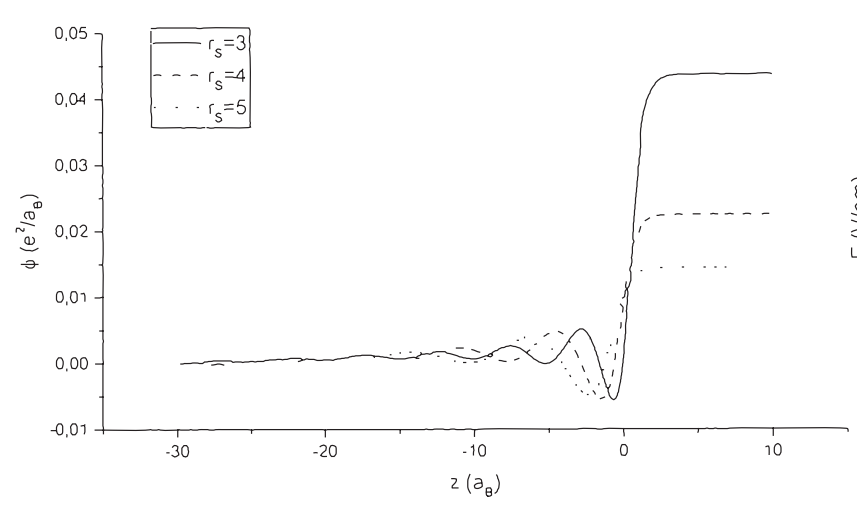

Fig. 4. Electrostatic potential $\varphi(z)$ for different values of $r_{s}$.

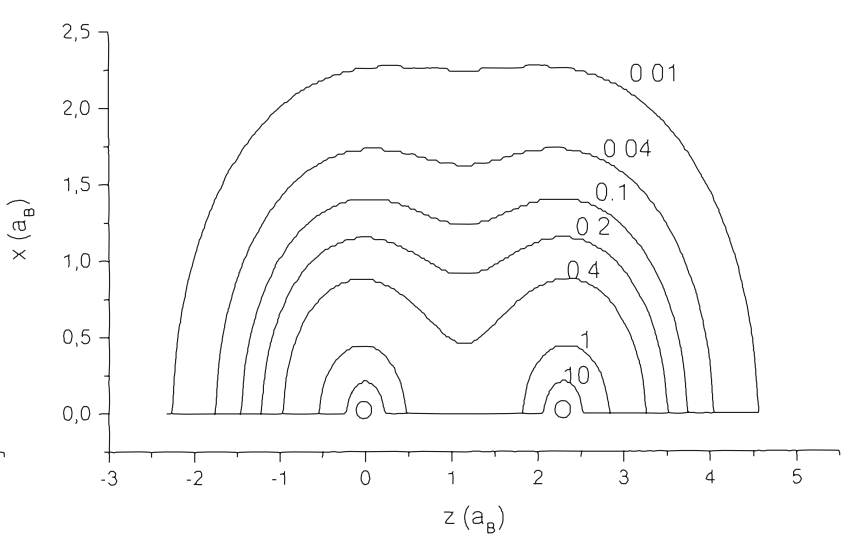

Fig. 3. Electronic density of $\mathrm{O}_{2}$ molecule obtained by using Firefly.

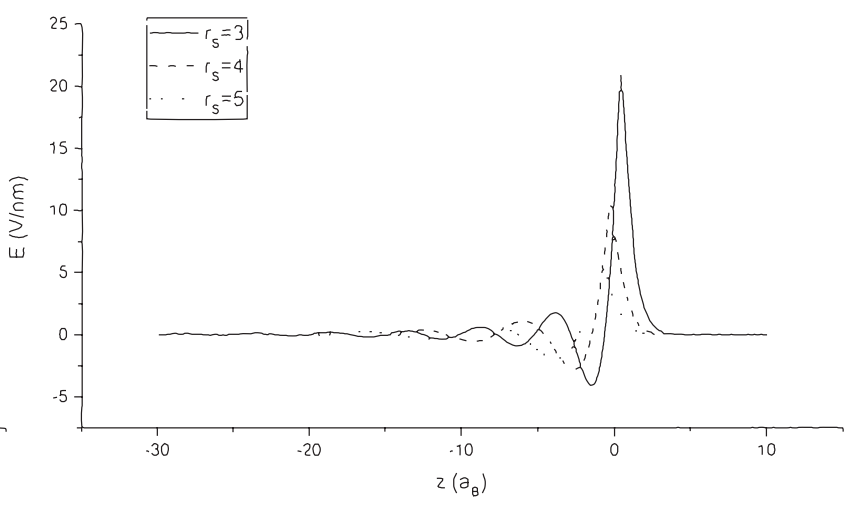

Fig. 5. Intensity $E(z)$ of field for different values of $r_{s}$.

\section{Calculation of flue gas and oxygen molecules energy near the catalyst surface}

Let us go back to the expression for the energy of diatomic molecule in an electric field (4):

$$
W-W_{0}=\frac{1}{2} \int_{V} \varphi(z) \rho^{e}(\boldsymbol{r}) d \boldsymbol{r}-\frac{1}{2} e\left(Q_{1} \varphi\left(z_{1}\right)+Q_{2} \varphi\left(z_{2}\right)\right)-d_{0 z} E\left(z_{d}\right)-\varepsilon_{0} \alpha E^{2}\left(z_{d}\right),
$$

In the first term, let us make a transformation from coordinate system of catalyst to coordinate system of the diatomic molecule (Fig. 1). Let $\boldsymbol{r}=(x, y, z)$ be coordinates in the catalyst coordinate system, $\boldsymbol{r}^{\prime}=\left(x^{\prime}, y^{\prime}, z^{\prime}\right)$ are coordinates in the molecule coordinate system. These coordinate systems are related by the correlations:

$$
\boldsymbol{r}^{\prime}=\boldsymbol{r}_{0}-A \boldsymbol{r}
$$

where $\boldsymbol{r}_{0}^{\prime}=\left(x_{0}^{\prime}, y_{0}^{\prime}, z_{0}^{\prime}\right)$ is a coordinate origin of molecule in catalyst coordinates, $A$ is a rotation matrix, which contains direction cosines between the axes.

$$
A=\left(\begin{array}{ccc}
\cos _{x x} & \cos _{x y} & \cos _{x z} \\
\cos _{y x} & \cos _{y y} & \cos _{y z} \\
\cos _{z x} & \cos _{z y} & \cos _{z z}
\end{array}\right)
$$

Whereas these relations are linear then inverse relations can be determined identically. Let $J$ be Jacobian matrix of the transformation from $\boldsymbol{r}$ to $\boldsymbol{r}^{\prime}$. Since a transformation is a rotation and does not 
depend on coordinates then the determinant $|J|$ is a constant. Hence we have that

$$
\frac{1}{2} \int_{V} \varphi(\boldsymbol{r}) \rho^{e}\left(\boldsymbol{r}^{\prime}(\boldsymbol{r})\right) d \boldsymbol{r}=\frac{1}{2}|J| \int_{V} \varphi\left(z\left(\boldsymbol{r}^{\prime}\right)\right) \rho^{e}\left(\boldsymbol{r}^{\prime}\right) d \boldsymbol{r}^{\prime} .
$$

Note, since in the explored model only the angle $\beta$ of the slope of the axis $z$ plays a role then one of the axes $x$ or $y$ is going to be unchangeable. Thus, the matrix (10) can be expressed as follows (for the unchangeable axis $x$ )

$$
A=\left(\begin{array}{ccc}
1 & 0 & 0 \\
0 & \cos \beta & -\sin \beta \\
0 & \sin \beta & \cos \beta
\end{array}\right)
$$

The determinant of this matrix is equal to 1 . Nondimensionalize the expression (11). Let

$$
\varphi=\varphi^{*} \frac{e}{a_{B}}, \quad \rho^{e}=\rho^{*} \frac{e}{a_{B}^{3}}, \quad d \boldsymbol{r}^{\prime}=a_{B}^{3} d \boldsymbol{r}^{*}
$$

Then, including that $|J|=1$,

$$
\frac{1}{2} \int_{V} \varphi\left(z\left(\boldsymbol{r}^{\prime}\right)\right) \rho^{e}\left(\boldsymbol{r}^{\prime}\right) d \boldsymbol{r}^{\prime}=\frac{1}{2} \frac{e^{2}}{a_{B}} \int_{V} \varphi^{*}\left(z^{*}\left(\boldsymbol{r}^{*}\right)\right) \rho^{*}\left(\boldsymbol{r}^{*}\right) d \boldsymbol{r}^{*}
$$

In a similar way to (11), let us nondimensionalize the second term related to nucleus:

$$
\frac{1}{2} e\left(Q_{1} \varphi\left(z_{1}\right)+Q_{2} \varphi\left(z_{2}\right)\right)=\frac{1}{2} \frac{e^{2}}{a_{B}}\left(Q_{1} \varphi^{*}\left(z_{1}^{*}\right)+Q_{2} \varphi^{*}\left(z_{2}^{*}\right)\right) .
$$

Let us analyze a contribution related to the presence of a dipole moment in a molecule. The dipole moment is directed towards the field by $O Z$ axis of catalyst coordinate system. Then

$$
d_{0 z}=d_{0} \cos \beta
$$

where $d_{0}$ is the value of the dipole moment of the molecule (for $C O$ molecule experimental value of $d_{0}$ is equal to 0.112 Debye, for $\mathrm{O}_{2}$ molecule it is equal to 0 ). Nondimensionalizing the last term in (4), we obtain

$$
\begin{aligned}
W-W_{0}= & \frac{e^{2}}{a_{B}}\left[\frac{1}{2} \int_{V} \varphi^{*}\left(z^{*}\left(\boldsymbol{r}^{*}\right)\right) \rho^{*}\left(\boldsymbol{r}^{*}\right) d \boldsymbol{r}^{*}+\frac{1}{2}\left(Q_{1} \varphi^{*}\left(z_{1}^{*}\right)+Q_{2} \varphi^{*}\left(z_{2}^{*}\right)\right)\right. \\
& \left.-0.00155\left(d_{0}^{*} \cos \beta E\left(z_{d}^{*}\right)+0.0026 \alpha^{*} E^{*}\left(z_{d}^{*}\right)\right)\right] .
\end{aligned}
$$

Further we minimize the expression for energy (15) for different values of the internuclear distance $\left|\boldsymbol{R}_{1}-\boldsymbol{R}_{2}\right|$ and for the angle $\beta$. In Figs. 6-11, there are represented numerical results of investigations of catalyst electric field influence on energy of flue gas and oxygen molecules in the distances $3 a_{B}, a_{B}, 0$ with the minimal possible distance of $m_{d}$ and $m_{d}-0.5 a_{B}$ (condition (7)) and the angles $\beta=0^{\circ}, 45^{\circ}, 90^{\circ}$. The Gell-Mann-Brueckner parameter is chosen specific to platinum $\left(r_{s}=4\right)$. Below the surface $z=m_{d}$, a positive charge lays and a molecule with respect to strong Coulomb repulsion in our model cannot enter. For $r_{s}=3 m_{d}=0.341 a_{B}$; for $r_{s}=4 m_{d}=-0.3 a_{B}$; for $r_{s}=5 m_{d}=-0.98 a_{B}$.

The results of numerical investigation of the proposed model show the following. For the $\mathrm{O}_{2}$ molecule, the equilibrium interatomic distance $R_{0}^{O_{2}}=\left|\boldsymbol{R}_{1}-\boldsymbol{R}_{2}\right|$ in the presence of electric field near the catalyst surface changes and for all the distances of the $\mathrm{O}_{2}$ molecule charge center from the catalyst 


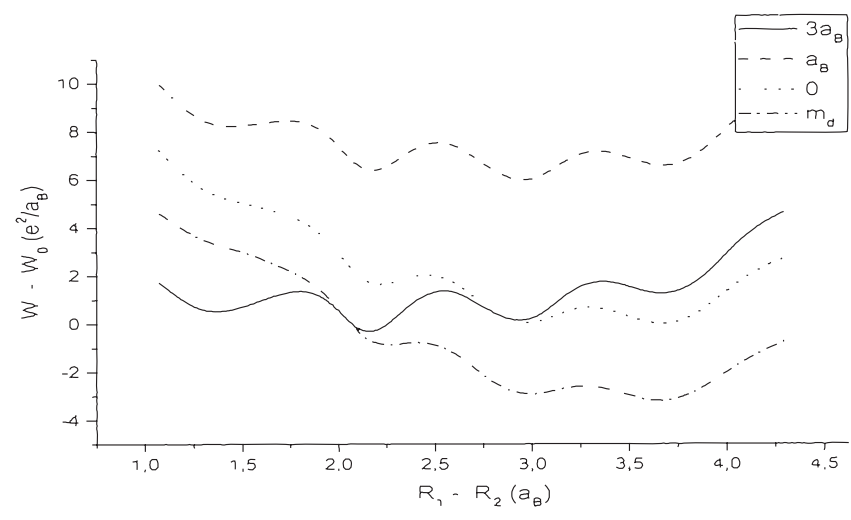

Fig. 6. Dependence of the energy (15) on internuclear distance of $C O$ for different distances to the surface for the angle of $\beta=0^{\circ}$.

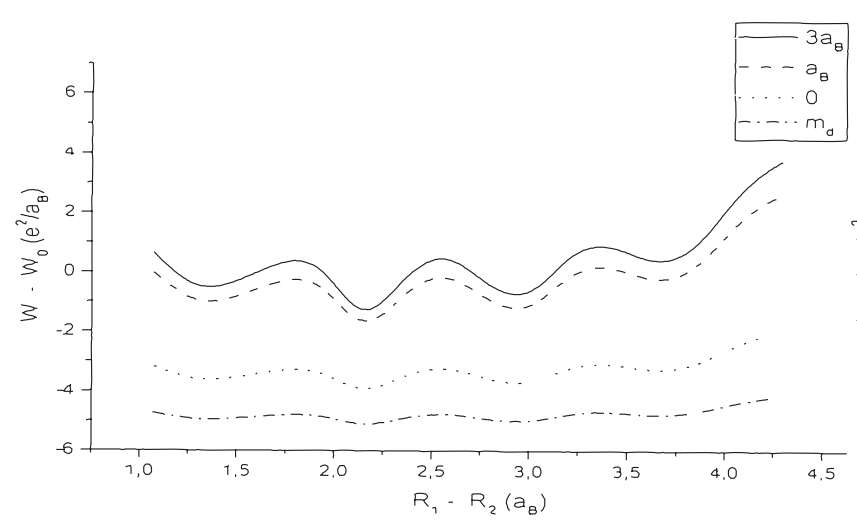

Fig. 8. Dependence of the energy (15) on internuclear distance of $C O$ for different distances to the surface for the angle of $\beta=90^{\circ}$.

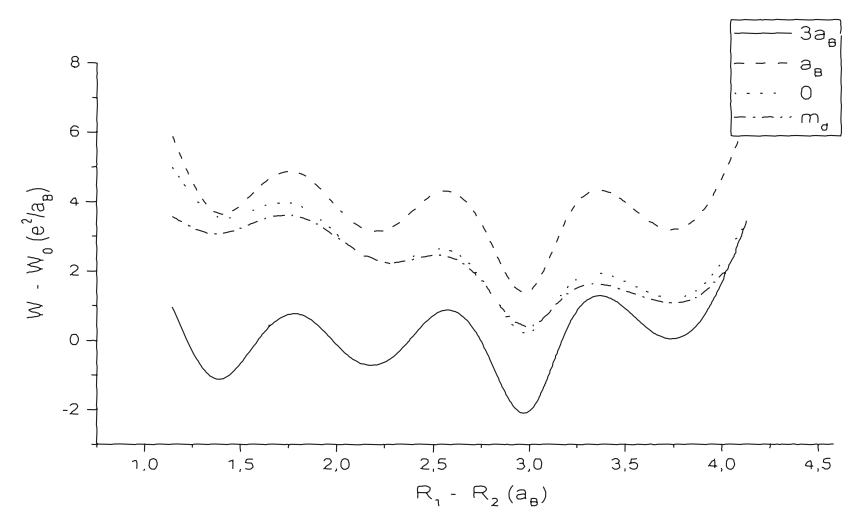

Fig. 10. Dependence of the energy (15) on internuclear distance of $C O$ for different distances to the surface for the angle of $\beta=45^{\circ}$.

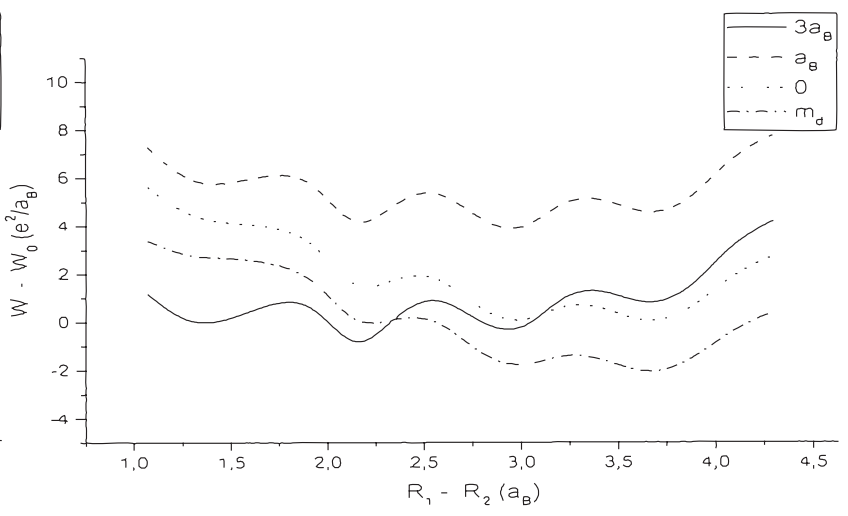

Fig. 7. Dependence of the energy (15) on internuclear distance of $C O$ for different distances to the surface for the angle of $\beta=45^{\circ}$.

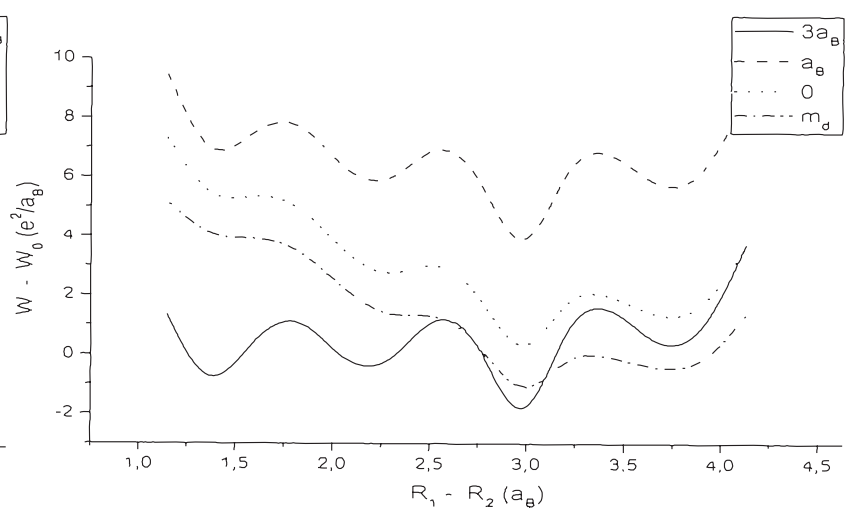

Fig. 9. Dependence of the energy (15) on internuclear distance of $\mathrm{O}_{2}$ for different distances to the surface for the angle of $\beta=0^{\circ}$.

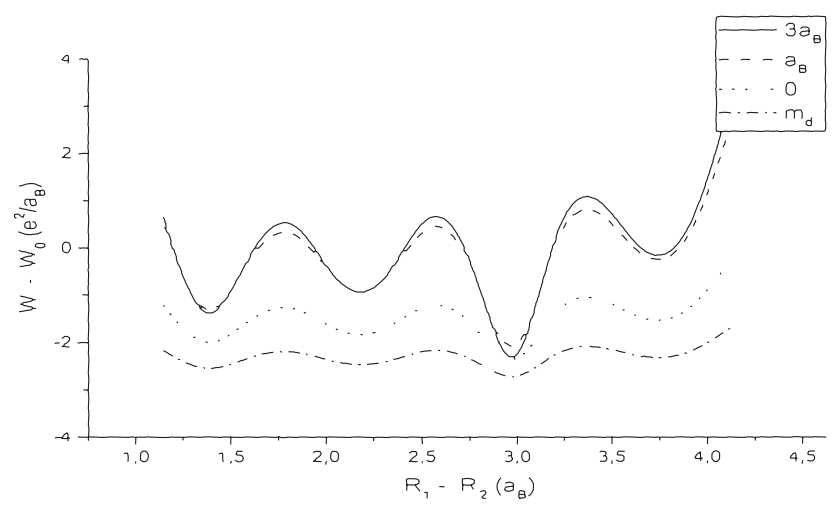

Fig. 11. Dependence of the energy (15) on internuclear distance of $C O$ for different distances to the surface for the angle of $\beta=90^{\circ}$. 
surface $R_{0}^{O_{2}}=2.22943 a_{B}$. It is $130 \%$ of the equilibrium distance $R_{0}^{O_{2}}$ when the electric field of catalyst is absent: $R_{0}^{O_{2}}=2.147 a_{B}$.

The energy change $\Delta E=E_{\min }(E \neq 0)-\varepsilon_{\min }(E=0)$ depends on the angle $\beta$ and is the following:

$$
\begin{gathered}
\beta=0^{\circ}: \Delta E=-1 \frac{e^{2}}{2 a_{B}}, \quad R_{0}^{O_{2}}=2.2942, \\
\beta=45^{\circ}: \Delta E=-0.5 \frac{e^{2}}{2 a_{B}}, \quad R_{0}^{O_{2}}=2.2942, \\
\beta=90^{\circ}: \Delta E=-3 \frac{e^{2}}{a_{B}}, \quad R_{0}^{O^{2}}=2.2942 .
\end{gathered}
$$

These results testify that the shown dipole moment $\boldsymbol{d}_{\mathrm{O}_{2}}$ of the molecule $\mathrm{O}_{2}$ when it is approaching the catalyst surface becomes parallel to the surface and the molecule becomes $\mathrm{O}_{2}$ asymmetric.

For the $C O$ molecule, the location of energy minimum $\left(R_{0}^{C O}\right)$ depends on the angle $\beta$ of the dipole moment and on the distance $r_{0}$ of the $C O$ molecule charge center from the surface of catalyst, namely

Table 1. Dependence of $C O$ molecule energy

minimum location on model parameters.

\begin{tabular}{|c|c|c|c|}
\hline$r_{0} / \beta$ & $0^{\circ} \div 50^{\circ}$ & $50^{\circ} \div 70^{\circ}$ & $70^{\circ} \div 90^{\circ}$ \\
\hline $1 \div 3$ & 2.147 & 2.147 & 2.147 \\
\hline $0 \div m_{d}$ & 3.650 & 3.00 & 2.147 \\
\hline
\end{tabular}

This table demonstrates that when the $C O$ molecule approaches the catalyst surface, it does not tend to decay into atoms (in contrast to $\mathrm{O}_{2}$ molecule).

\section{Conclusions}

A simple mathematical model of diatomic molecule $\left(\mathrm{CO}\right.$ or $\left.\mathrm{O}_{2}\right)$ behavior description near the Ptcatalyst surface is suggested and investigated. It is shown that a near-surface electric field has a significant influence on the change (or appearance) of dipole moment of molecules and changes the equilibrium interatomic distance. The changes of these characteristics for the molecules $\mathrm{CO}$ and $\mathrm{O}_{2}$ are evaluated.

[1] Kostrobij P. P., Tokarchuk M. V., Markovich B. M., Ignatjuk V. V., Gnativ B. V. Reakcijno-difuzijni procesy v sistemah "metal-gaz". Lviv, Lviv Polytechnic National University (2009), (in Ukrainian).

[2] Richardson J. T. Principles of Catalyst Development, Springer Science+Business Media, LLC (1992).

[3] Rideal E. K. Concepts in Catalysis, Academic Press (1968).

[4] Baxter R. J., Hu P. Insight into why the Langmuir-Hinshelwood mechanism is generally preferred. J. Chem. Phys. 116, n. 11, 4379-4381 (2002).

[5] Zhang C., Hu P., Alavi A. A general mechanism for CO oxidation mechanism on close-packed transition metal surfaces. J. Am. Chem. Soc. 121, 7931-7932 (1999).

[6] Zhdanov V. P., Kasemo B. Simulation of CO adsorbtion and oxidation on Pt(110). Phys. Rev. B. 114, n. $12,5351-5357$ (2001).

[7] Reuter K., Frenkel D., Scheffler M. The steady-state of heterogeneous catalysis, studied by first-principles statistical mechanics. Preprint cond-mat. 0408080 v.l (2004).

[8] Mryglod I. M., Bzovska I. S. Effect of adsorbed impurities on catalytic oxidation of CO: a lattice-gas model. Ukr. J. Phys. 52, n. 5, 466-471 (2007).

[9] Ziff R. M., Gulari E., Barshad Y. Kinetic phase transitions in an irreversible surface reaction model. Phys. Rev. Letters. 56, n. 24, 2553-2556 (1986).

Mathematical Modeling and Computing, Vol. 3, No. 1, pp. 43-50 (2016) 
[10] Johanek V., Laurin M., Grant A. W., Kasemo B., Henry C. R., Libuda J. Fluctuations and bistabilities on catalyst nanoparticles. Science. 304, 1639-1644 (2004).

[11] Kostrobiy P. P., Markovych B. M., Suchorski Y. Revisiting local electric fields on a closed-packed metal surfaces: theory versus experiments. Solid state phenomena. 128, 219-224 (2007).

[12] Kostrobij P. P. Doctoral Thesis. Reaction-diffusion processes in systems with a "metal-gas" interface: the quantum statistical description. Lviv (2009), (in Ukrainian).

[13] Kostrobij P. P., Markovych B. M. Statistical theory of the spacebounded systems of charged fermi-particles: I. The functional integration method and effective potentials. Journ. of Phys. Stud. 7, 195-206 (2003) (in Ukrainian).

[14] Vakarchuk I. O. Kvantova mehanika. Lviv, Lviv National University (2004), (in Ukrainian).

[15] Kostrobij P. P., Markovych B. M. Investigation of the Influence of External Electric Field on the Electron Density of Semi-bounded Metal. Ukr. J. Phys. 52, n. 2, 167-171 (2007).

[16] Fudzinaga C. Metod molekuljarnih orbitalej. Moskva, Mir (1983), (in Russian).

[17] Kostrobij P. P., Markovych B. M. Statistical theory of the spacebounded systems of charged fermi-particles: II. Distribution functions. Journ. of Phys. Stud. 7, 298-312 (2003) (in Ukrainian).

[18] Granovsky Alex A. Firefly version 8, wwww http://classic.chem.msu.su/gran/firefly/index.html.

\title{
Моделювання впливу поверхні Pt-каталізатора на характеристики молекул кисню і окису вуглецю
}

\author{
Костробій П. П. ${ }^{1}$, Безносюк А. В. ${ }^{1}$, Дмитрук В. А. ${ }^{1,2}$, Польовий В. Е. ${ }^{1}$ \\ ${ }^{1}$ Національний університет «Львівсъка політехніка» \\ вул. С. Бандери, 12, 79013, Львів, Україна \\ ${ }^{2}$ Центр математичного моделювання ІППММ ім. Я. С. Підстригача \\ Начіональної академії наук Украӥни \\ вул. Дудаєва, 15, 79005, Лъвів, Україна
}

Розглянуто просту математичну модель впливу поверхні Pt-каталізатора на поведінку молекул чадного газу та кисню. Показано, що електричне поле, локалізоване в приповерхневому шарі Pt-каталізатора, призводить до значної зміни дипольного моменту та рівноважної міжатомної відстані.

Ключові слова: двоатомні молекули в електричному полі, явище каталізу, півобмежений метал.

2000 MSC: $00 \mathrm{~A} 71$

UDC: $533.9,536.7$

Mathematical Modeling and Computing, Vol.3, No.1, pp. 43-50 (2016) 